\title{
Emergency and critical care services in Tanzania: a survey of ten hospitals
}

Tim Baker ${ }^{1,2^{*}}$, Edwin Lugazia $^{3}$, Jaran Eriksen ${ }^{4}$, Victor Mwafongo ${ }^{3}$, Lars Irestedt ${ }^{1,2}$ and David Konrad ${ }^{1,2}$

\begin{abstract}
Background: While there is a need for good quality care for patients with serious reversible disease in all countries in the world, Emergency and Critical Care tends to be one of the weakest parts of health systems in low-income countries. We assessed the structure and availability of resources for Emergency and Critical Care in Tanzania in order to identify the priorities for improving care in this neglected specialty.

Methods: Ten hospitals in four regions of Tanzania were assessed using a structured data collection tool. Quality was evaluated with standards developed from the literature and expert opinion.

Results: Important deficits were identified in infrastructure, routines and training. Only 30\% of the hospitals had an emergency room for adult and paediatric patients. None of the seven district and regional hospitals had a triage area or intensive care unit for adults. Only 40\% of the hospitals had formal systems for adult triage and in less than one third were critically ill patients seen by clinicians more than once daily. In $80 \%$ of the hospitals there were no staff trained in adult triage or critical care. In contrast, a majority of equipment and drugs necessary for emergency and critical care were available in the hospitals (median 90\% and 100\% respectively. The referral/private hospitals tended to have a greater overall availability of resources (median 89.7\%) than district/regional hospitals (median 70.6).

Conclusions: Many of the structures necessary for Emergency and Critical Care are lacking in hospitals in Tanzania. Particular weaknesses are infrastructure, routines and training, whereas the availability of drugs and equipment is generally good. Policies to improve hospital systems for the care of emergency and critically ill patients should be prioritised.
\end{abstract}

Keywords: Emergency medicine, Critical care, Health services, Quality of health care, Developing countries, Africa, Tanzania, Triage

\section{Background}

Emergency and Critical Care (EaCC) is one of the weakest parts of health systems in low-income countries [1]. Defined as the care given in hospital to patients with serious reversible disease, EaCC encompasses both the emergency care on arrival plus the care of inpatients when in a critical state. There is a need for EaCC in all countries in the world, irrespective of local resources [2]. The global burden of critical illness is difficult to quantify but is especially high in developing countries $[3,4]$.

\footnotetext{
* Correspondence: timothy.baker@karolinska.se

'Department of Physiology and Pharmacology, Section for Anaesthesiology and Intensive Care Medicine, Karolinska Institute, Stockholm, Sweden

${ }^{2}$ Department of Anaesthesia, Intensive Care and Surgical Services, Karolinska University Hospital, Stockholm 171 76, Sweden

Full list of author information is available at the end of the article
}

Ninety percent of trauma deaths and ninety percent of deaths from pneumonia, meningitis and other infections occur in low or middle income countries $[5,6]$. Ninetynine percent of global maternal mortality is in developing countries [7]. Seventy-Five percent of the 7.6 million children under 5 who die each year worldwide are in Africa or Asia [8]. Fifty percent of child deaths in hospitals in developing countries occur within 24 hours of arriving at the hospital [9].

Although the majority of critically ill patients in developing countries are children and young adults, reported fatality rates are high: mortality for severe head injury in Benin is $70 \%$ and mortality for septic shock in Tunisia is $82 \%$ [10]. Several studies have reported deficiencies in care for seriously ill children $[11,12]$ and in emergency 
obstetric care [13] in low-income countries. However, to our knowledge, there are no published studies looking at the quality of EaCC across all disciplines and no singlecountry analyses of EaCC services [14].

Tanzania is a politically stable, low-income country in East Africa. With a population of 44 million, Tanzania is ranked 152 out of 187 countries in the Human Development Index [15] (see Table 1). While Tanzania has some discipline-specific guidelines such as for obstetrics [16] or malaria [17], there are no national guidelines specifically for EaCC. The state of the services provided for the critically ill in Tanzania is largely unknown. In this study we aim to describe the structure and availability of hospital resources for $\mathrm{EaCC}$ in Tanzania as a starting point for the identification of priorities for improving care for this neglected patient group.

\section{Methods}

There are 21 regions in mainland Tanzania and 223 hospitals [19]. Ten hospitals were selected for study feasibility from four regions of the country using convenience sampling, ensuring a mix of district, regional, referrallevel and private hospitals. The hospitals were studied on single day visits by two of the investigators (EL and TB) between October and November 2009 after prior telephone contact. The investigators conducted the first five visits together so as to harmonise the conduct of the visits and how to collect the data. The subsequent five visits were done by a single investigator (two by EL, three by TB). The data was collected using a structured tool which further ensured consistency in data collection. A structured interview was conducted with the head of the hospital and all areas of the hospital involved in $\mathrm{EaCC}$ were visited and the facilities assessed using a data collection tool divided into hospital specialties to ensure that the facilities for all patient groups were observed (available in the Additional file 1).

As there have not been any published Tanzanian or international guidelines specifically for EaCC in lowincome countries, we first developed a set of standards. Three of the researchers (TB, DK, JE) reviewed the literature and extracted relevant standards from international guidelines for trauma [20], paediatrics [21,22], surgery $[23,24]$ and anaesthesia [25]. We used an "expert

Table 1 Tanzania demographics

\begin{tabular}{lr}
\hline Population & $\mathbf{4 4}$ million \\
\hline Gross National Income per capita (US Dollars) & 1430 \\
Life Expectancy at birth (years) & 55 \\
Physicians (per 100,000 population) & 0.1 \\
Under-five mortality rate (per 1000) & 76 \\
Maternal mortality ratio (per 100,000 live births) & 460 \\
\hline
\end{tabular}

All data from World Health Statistics 2012 [18]. group" process to revise these standards. The expert group was comprised of the six researchers plus ten anaesthesiologists and physicians currently working or with recent experience of working in low-income countries (see acknowledgements). The researchers conducted several face-to-face meetings and the expert group were consulted via email and telephone. Due to resource and time constraints we were unable to organise a formal Delphi method or a face-to-face meeting of the whole expert group. A final document of 104 indicators were decided upon that describe the minimal structural requirements for $\mathrm{EaCC}$ in low-income countries (available in the Additional file 2).

For the purposes of this study, 19 of the indicators were disregarded. This decision was taken by the researchers prior to data collection due to the risk that the many drug and equipment indicators (60 of the 104 indicators) would weigh the study too greatly towards the availability of these items. To assess whether the hospitals had extra resources beyond the minimum required for $\mathrm{EaCC}$ we selected a further ten indicators for "Advanced EaCC" from international best-practice guidelines [26]. Processes and outcomes of $\mathrm{EaCC}$ were not evaluated.

The indicators were divided into eight sections: infrastructure; human resources; training; drugs; equipment; routines; guidelines; support services. Where data was missing from four or more hospitals the indicator was excluded (apart from indicators in the routines and guidelines sections where missing data was judged likely to be due to an absence in the hospital). The hospitals were stratified into two groups: district/regional and referral/private as we hypothesised that resources would differ between the groups. We calculated the proportion of hospitals where each resource was available. We calculated a "resource availability score" for each hospital, subdivided into indicator sections, as percentages of available resources with missing data excluded. Due to the small sample size, inferential statistics were not used.

Ethical clearance was granted by the National Institute for Medical Research in Tanzania (NIMR/HQ/R.8a/Vol. IX/846) and permission for the study was granted by The Tanzanian Commission for Science and Technology (Costech) and district authorities in each study district. All interviewees gave informed consent to participate and were informed that they could withdraw from the study at any time.

\section{Results \\ Hospital characteristics}

Of the ten hospitals included in the study, four were district hospitals (secondary care), three were regional hospitals (tertiary care), two were national referral hospitals (quaternary care) and one was a privately owned mission 
hospital (Table 2). The hospitals were located in four regions with a total population of 6.8 million (18\% of the population of mainland Tanzania) [19]. All the hospitals divided patients up into specialty with separate admissions systems for adults and children. Obstetric patients were seen directly in the obstetric wards and were excluded from the analysis.

\section{Quality of EaCC}

Of the 104 indicators in the standards, 74 were used for the analysis. Nineteen equipment and drug indicators were disregarded to avoid weighting the study too greatly towards these items and eleven indicators were excluded due to missing data from four or more hospitals. The availability of each resource is shown in Table 3. A "Resource Availability Score" was calculated as the percentage of resources available in each hospital. The scores ranged from $57.1 \%$ to $92.1 \%$ with a median of 71.1\% (Table 4). The referral/private hospitals had higher scores (median 89.7\%) than district/regional hospitals (median 70.6\%). Across all hospitals scores for infrastructure resources $(50.0 \%)$ and for EaCC routines (42.2\%) were lower than drugs (100\%) and equipment (90.0\%) (Figure 1).

\section{Infrastructure}

In three hospitals there was a triage area for adults, and three hospitals had a triage area for children. Three hospitals had an emergency room (ER) for both children and adults. A further three had an ER for adults only and two hospitals had an ER for children only. Where an ER was not present the general outpatients department or the inpatient wards were used for emergency patients. Three hospitals had a ward that was designated as an Intensive Care Unit (ICU). The level of critical care provided on the ICUs varied: from ventilators and electronic patient monitors to a simple increase in the nurse: patient ratio and more frequent patient observations. In the other hospitals critically ill patients were cared for on general wards; two hospitals had a specific ward area for critically ill adults and nine hospitals had designated beds for critically ill children. The referral/ private hospitals had a greater availability of infrastructure resources (median 100\%) than district/regional (median $50 \%$ ). None of the district hospitals had a triage area, Emergency Room or an ICU.

\section{Human resources}

Specialist Anaesthesiologists (the specialty in Tanzania responsible for Critical Care) were present in only the two referral hospitals. In two hospitals the anaesthetic service was staffed solely by nurses. In the other hospitals non-physician clinicians were present alongside nurses. These included Clinical Officers (staff with three years of college training) and Assistant Medical Officers (Clinical Officers with two further years of clinical training). Anaesthetic staffing was low in comparison to other medical staff (Table 2).

\section{Training}

In none of the hospitals had all the staff involved in EaCC been trained in triage, emergency care or critical care. The indicators were therefore adjusted to show if hospitals had "any" staff instead of "all" staff trained. Twenty percent of hospitals had at least one staff trained in adult triage and $20 \%$ had at least one staff trained in adult critical care. Training was most prevalent in Paediatric critical care with $80 \%$ of hospitals with at least one trained staff. Three hospitals $(30 \%)$ had at least one staff who had been trained in the World Health Organisation's paediatric training in "Emergency Triage \& Treatment" (ETAT) [21].

Table 2 Hospital characteristics

\begin{tabular}{|c|c|c|c|c|c|c|c|c|c|c|}
\hline & \multicolumn{10}{|c|}{ Hospitals } \\
\hline & 1 & 2 & 3 & 4 & 5 & 6 & 7 & 8 & 9 & 10 \\
\hline Type & District & District & District & District & Regional & Regional & Regional & Referral & Private & Referral \\
\hline Region & 1 & 2 & 2 & 2 & 3 & 4 & 1 & 2 & 2 & 4 \\
\hline Number of beds & $<200$ & $200-400$ & $200-400$ & $200-400$ & $>400$ & $200-400$ & $200-400$ & $>400$ & $<200$ & $>400$ \\
\hline $\begin{array}{l}\text { Number of specialist doctors } \\
\text { (excluding anaesthesiologists) }\end{array}$ & 2 & 6 & 6 & 8 & 7 & 1 & 5 & $>50$ & 18 & 25 \\
\hline Number of specialist anaesthesiologists & 0 & 0 & 0 & 0 & 0 & 0 & 0 & 6 & 0 & 1 \\
\hline Number of non-specialist clinician anaesthetists & 0 & 3 & 3 & 1 & 1 & 3 & 3 & 12 & 0 & 4 \\
\hline ICU & No & No & No & No & No & No & No & Yes & Yes & Yes \\
\hline Number of operating theatres & 1 & $\mathrm{n} / \mathrm{a}$ & 2 & 2 & 5 & 2 & 1 & 11 & n/a & 9 \\
\hline
\end{tabular}

Number of beds divided into three groups: $<200 ; 200-400 ;>400$. 
Table 3 Percentage availability of resources for emergency and critical care

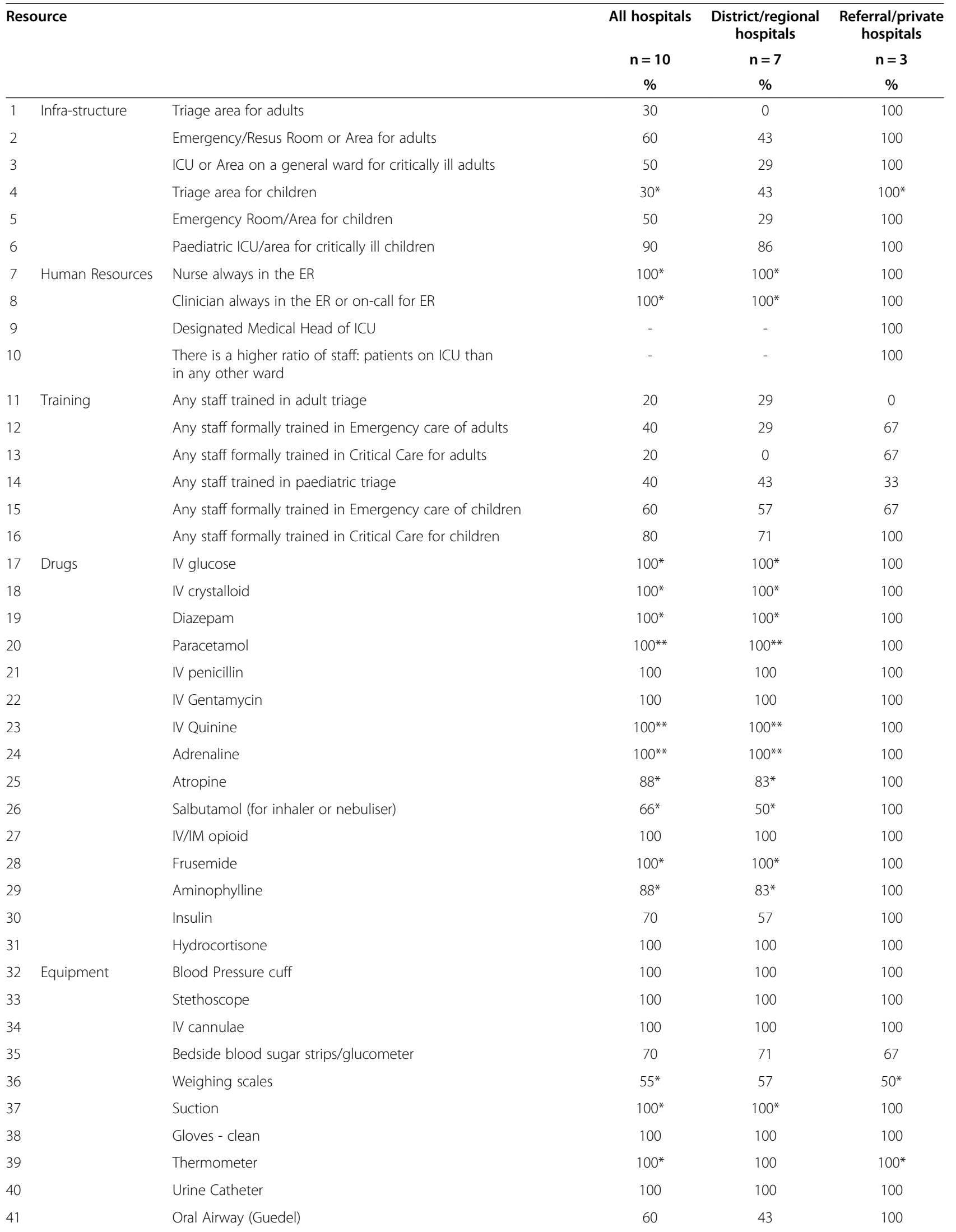


Table 3 Percentage availability of resources for emergency and critical care (Continued)

\begin{tabular}{|c|c|c|c|c|c|}
\hline 42 & & Pulse oximeter & 70 & 57 & 100 \\
\hline 43 & & Naso-gastric Tubes & 100 & 100 & 100 \\
\hline 44 & & $\begin{array}{l}\text { Oxygen concentrator/cylinder with face masks or nasal prongs } \\
\text { and tubing }\end{array}$ & 90 & 86 & 100 \\
\hline 45 & & Electricity 24 hours/day & 50 & 29 & 100 \\
\hline 46 & & Running Water \& soap & 100 & 100 & 100 \\
\hline 47 & Routines & $\begin{array}{l}\text { Formal system for categorising new adult patients according to } \\
\text { urgency }\end{array}$ & 40 & 14 & 100 \\
\hline 48 & & Formal system for prioritising critically ill adults & $44^{*}$ & $16^{*}$ & 100 \\
\hline 49 & & $\begin{array}{l}\text { Registration/Payment delayed until after triage \& emergency } \\
\text { treatment of critically ill adults }\end{array}$ & $85^{* * *}$ & $80^{* *}$ & $100^{*}$ \\
\hline 50 & & Nurses do more frequent observations on critically ill adults & $83^{* * * *}$ & $66^{* * * *}$ & 100 \\
\hline 51 & & Ward rounds are done for critically ill adults at least twice a day & 30 & 0 & 100 \\
\hline 52 & & $\begin{array}{l}\text { Formal system for categorising new paediatric patients according } \\
\text { to urgency }\end{array}$ & $57^{* * *}$ & $50^{*}$ & $100^{* *}$ \\
\hline 53 & & Formal system for prioritising critically ill children & - & $50^{*}$ & - \\
\hline 54 & & $\begin{array}{l}\text { Registration/Payment delayed until after triage \& emergency } \\
\text { treatment of critically ill children }\end{array}$ & - & $100^{* * * *}$ & - \\
\hline 55 & & Nurses do more frequent observations on critically ill children & $77^{*}$ & $66^{*}$ & 100 \\
\hline 56 & & Ward rounds are done for critically ill children at least twice a day & $33^{*}$ & $0^{*}$ & 100 \\
\hline 57 & & ICU admission criteria & - & - & $50^{*}$ \\
\hline 58 & & $\begin{array}{l}\text { "Track and trigger" system on the wards for finding and referring } \\
\text { critically ill patients to the ICU }\end{array}$ & - & - & $0^{*}$ \\
\hline 59 & Guidelines & Triage Guidelines for adults & $13^{* *}$ & $0^{* *}$ & 33 \\
\hline 60 & & Guidelines for resuscitation/emergency care of adults & $14^{* * *}$ & $0^{* *}$ & $50^{*}$ \\
\hline 61 & & Guidelines for managing seriously ill adults & $20^{* * * * *}$ & $0^{* * * *}$ & $50^{*}$ \\
\hline 62 & & Triage Guidelines for children & - & $25^{* * *}$ & - \\
\hline 63 & & Resuscitation Guidelines for children & - & $25^{* * *}$ & - \\
\hline 64 & & Guidelines for managing seriously ill children & - & $33^{*}$ & - \\
\hline 65 & & Guidelines for oxygen use & $14^{* * *}$ & $25^{* * *}$ & 0 \\
\hline 66 & Support Services & Lab with facilities to measure Haemoglobin & 100 & 100 & 100 \\
\hline 67 & & Lab with facilities to measure Blood Glucose & 100 & 100 & 100 \\
\hline 68 & & $\begin{array}{l}\text { Lab with facilities to measure Serum Urea/Creatinine, Sodium } \\
\text { and Potassium }\end{array}$ & 90 & 86 & 100 \\
\hline 69 & & Chest $X$-ray facilities & 100 & 100 & 100 \\
\hline 70 & & System for emergency Blood Transfusion & 100 & 100 & 100 \\
\hline 71 & & System for making cross-matched blood available within one hour & 80 & 86 & 67 \\
\hline 72 & & System for testing donor blood for the viruses HIV, Hepatitis B \& C & $100^{* * *}$ & $100^{* *}$ & $100^{*}$ \\
\hline 73 & & Lab with facilities for microscopy \& Bacterial Gram stain & 100 & 100 & 100 \\
\hline 74 & & Lab with facilities for bacterial culture and antibiotic sensitivities & 80 & 71 & 100 \\
\hline
\end{tabular}

Data given as a percentage of the hospitals where each resource was available.

* missing data is shown with one asterix $\left(^{*}\right)$ per missing hospital. Where data is missing for all hospitals in a section a dash is shown (-).

ER Emergency Room; ICU Intensive Care Unit; IV Intravenous; IM Intramuscular.

\section{Drugs and equipment}

Intravenous fluids, parenteral opioids, diazepam, and antibiotics were available in all the hospitals where data was accessible as were blood pressure cuffs, naso-gastric tubes, suction machines and gloves. Oxygen was available in nine of the ten hospitals. Oro-pharyngeal airways were only found in six hospitals and salbutamol for inhalation in six out of nine hospitals. Reliable electricity with a backup generator was present in $50 \%$ of the hospitals (one of the district hospitals, one of the regional and all of the 
Table 4 Emergency and critical care resource availability scores*, by section

\begin{tabular}{|c|c|c|c|c|}
\hline & & & District/regional hospitals & Referral/private hospitals \\
\hline & & & $n=7$ & $n=3$ \\
\hline & Median & Range & Median & Median \\
\hline All indicators & 71.1 & $57.1-92.1$ & 70.6 & 89.7 \\
\hline Infrastructure & 50.0 & 16.7-100 & 50.0 & 100 \\
\hline Human Resources & - & - & - & 100 \\
\hline Training & 41.7 & $16.7-66.7$ & 33.3 & 66,7 \\
\hline Drugs & 100 & 71.4-100 & 86.7 & 100 \\
\hline Equipment & 90.0 & $64.3-100$ & 86.7 & 100 \\
\hline Routines & 42.2 & $12.5-100$ & 25.0 & 88.9 \\
\hline Guidelines & 17.1 & $0-100$ & 14.3 & 25 \\
\hline Support Services & 100 & $75.0-100$ & 100 & 100 \\
\hline
\end{tabular}

* Resource availability scores calculated as a percentage of the resources available in each hospital. Averages calculated as the median score of the hospitals. - missing data.

referral and private hospitals). The district/regional hospitals had slightly less availability of drugs and equipment than the referral/private hospitals (medians 86.7\%, 100\% respectively).

\section{Routines and written guidelines}

Forty percent of hospitals had formal systems of triage for adults and $44 \%$ had systems for prioritising the management of critically ill adults. Similar rates were seen for children. Registration and payment was delayed until after triage and emergency treatment at all hospitals for children and all except one for adults. Once admitted, $83 \%$ of hospitals had routines for increasing the frequency of observations for critically ill adults. However, ward rounds by clinicians were carried out more than

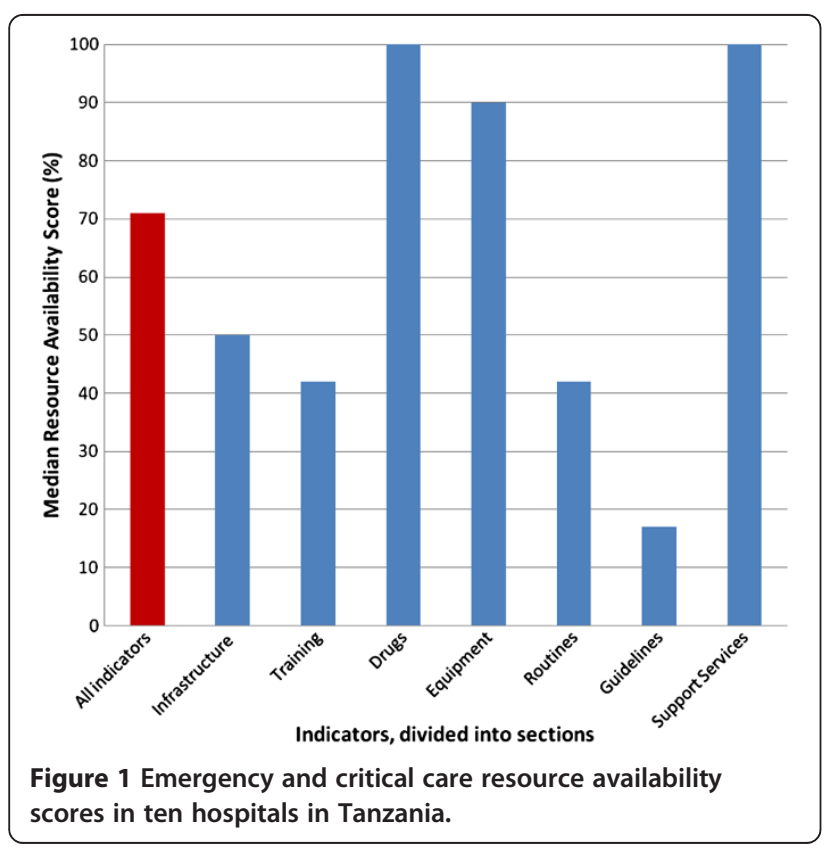

once daily in only $30 \%$ and $33 \%$ of hospitals for critically ill adults and children respectively. There were no written guidelines for adult triage, emergency treatment or critical care in any of the district or regional hospitals.

\section{Support services}

All hospitals had the facilities for checking haemoglobin, conducting bacterial gram stain, and performing chest x-rays. $80 \%$ of hospitals could perform bacterial cultures and sensitivities, 90\% could measure serum electrolytes. All hospitals could give emergency blood transfusions, $80 \%$ could do this within one hour of receiving a blood group specimen.

\section{Advanced EaCC}

Mechanical ventilators were present in $40 \%$ of hospitals, arterial blood gas monitoring in $20 \%$ and central venous pressure monitoring in 1 hospital of 10 (data not shown). A median of $25.0 \%$ of all indicators were available across all hospitals, with $20 \%$ in district/regional hospitals and $80 \%$ in referral/private hospitals.

\section{Discussion}

We have shown that hospitals in Tanzania lack many structures necessary for Emergency and Critical Care (EaCC). Our study has found that the weakest parts of EaCC are an infrastructure that is not designed for managing critically ill patients, a lack of routines for the prioritisation and management of the critically ill and a low level of EaCC training among staff. In contrast, we have shown that hospitals are well stocked with drugs and equipment necessary for EaCC. Our study highlights the quality gap between the better resourced referral and private hospitals and the less resourced district and regional hospitals suggesting that while there is some 
capacity for EaCC in Tanzania, it hasn't reached out to the smaller centres.

This study is, as far as we know, the first attempt to analyse the structural capacity for EaCC in a low-income country. As such its strengths are in highlighting this pressing need, to introduce standards for $\mathrm{EaCC}$ and to suggest likely causes of the reported weak performance and poor outcomes of $\mathrm{EaCC}$ in low-income countries $[10,27]$. Similar insights can be seen from the Tanzanian Service Provision Assessment Survey 2006 [28] where only $19 \%$ of hospitals nationwide had the facilities to support 24-hour emergency services and from studies focusing on paediatric inpatient care [12,29].

The sample size of ten hospitals is the study's main weakness, limiting the generalisability to the whole country, and the single-country setting limits international generalisability. The experience of the authors is, however, that similar findings can be seen in many other hospitals in Tanzania. Recent studies in related disciplines have shown findings consistent with our results in the Gambia [30], Zambia [31], Mongolia [32] and in sub-Saharan Africa [33]. A further limitation is the lack of some data due to unavailability of information when the hospital visits were conducted. The processes and outcomes of EaCC were not observed in this study; the existence of certain equipment in a hospital does not mean it is in working order or in the correct place, used for the correct patients and at the correct time.

So why is the quality of EaCC so poor? It has not been prioritised politically or medically as it cuts across many disciplines, is not age or disease specific and there are very few Emergency or Intensive Care specialists. There is a belief that EaCC requires sophisticated or expensive equipment, although the basic $\mathrm{EaCC}$ that is the focus in this study such as adequate fluid resuscitation, intravenous dextrose for hypoglycaemia and oxygen for hypoxia are not expensive [34]. In our experience, fatalism among staff with low morale is common and selffulfilling. Improving the service could lead to decreasing mortalities, which in turn could challenge fatalism. Vertical programs, while successfully tackling single diseases, have been less successful at strengthening health systems [35]. Programs for Essential Trauma Care [20], Emergency Obstetric Care [36], Hospital Care for Sick Children [22], Integrated Management for Adolescent and Adult Care [37] and Emergency and Essential Surgical Care $[30,38]$ have all been initiated by the WHO in the past few years. A common theme is the view that improving care for very sick patients is urgently required and would have the potential of reducing preventable mortality. A focus on EaCC could be a way of coordinating efforts in these programs.

There is a potential for improvement in EaCC. Recognising very sick patients quickly and instituting simple treatments has been the focus of much recent work in high-income countries with the introduction of Rapid Response Teams $[39,40]$. The same principles apply in lowincome settings: one study from Tanzania has shown that simple triage using vital signs can predict which patients have a high risk of mortality [41]. Reorganising a paediatric hospital admissions system in Malawi to include triage and emergency care reduced hospital mortality by $50 \%$ [42]. Intensive Care Units providing basic critical care are likely to be cost-effective due to a concentration of staff, skills and equipment close to the patients who need it most [43].

Improving levels of training is a vital issue in Tanzania and other low-income countries [44]. Critical Care is a subspecialty of Anaesthesia in Tanzania, and there are less than 20 specialist anaesthesiologists for a country of over 40 million people. Before 2009, when the first postgraduate training for doctors in Emergency Medicine was initiated, Tanzania had not trained any doctors in the speciality. Aside from the WHO's paediatric ETAT program, there was little evidence of training courses in Tanzania in caring for emergency or critically ill patients. The almost complete lack of guidelines that we observed implies that standardised and evidenced based care is not being followed. Although guidelines alone have not always been seen to improve outcomes they may have the potential to improve quality of care if introduced through a multifaceted approach, targeting knowledge, motivation, resources, and the organisation of care [45-47]. These patients do not have the luxury of waiting, and introducing training, routines and guidelines to improve the processes of care may lead to reduced mortality and morbidity.

A striking finding in the study is how well stocked the hospitals were with drugs and equipment necessary for basic EaCC. This suggests that a lack of the basic tools for EaCC cannot be blamed for deficiencies in the quality of care. Drugs and equipment for advanced care were mostly absent, but this should be seen rather as a rational prioritisation of resources than as a deficiency.

\section{Conclusions}

This study indicates to policy makers that improving the hospital systems for the care of emergency and critically ill patients in Tanzania should be prioritised. Improving the routines for managing these patients, increasing the human resources and training levels and improving the infrastructure may be the best ways to achieve this. Further research is required into the quality of the processes of EaCC and intervention studies are needed to assess the mortality and morbidity reductions and costeffectiveness of improving EaCC. 


\section{Additional files}

\section{Additional file 1: Data collection tool. \\ Additional file 2: Structure standards for emergency and critical care in low income countries.}

\section{Abbreviations}

EaCC: Emergency and critical care; ER: Emergency room; ETAT: Emergency triage and treatment; ICU: Intensive care unit.

\section{Competing interests}

All the authors declare that they have no competing interests.

\section{Authors' contributions}

TB contributed to the conception and design of the study, acquired, analyzed and interpreted the data, and drafted and revised the manuscript. EL contributed to the design of the study, acquired the data and critically revised the manuscript. JE contributed to the conception and design of the study and critically revised the manuscript. VM contributed to the conception of the study and critically revised the manuscript. LI contributed to the conception of the study and critically revised the manuscript. DK contributed to the conception and design of the study, analyzed and interpreted the data and critically revised the manuscript. All authors read and approved the final manuscript.

\section{Acknowledgements}

Thank you to Isabeau Walker, Ray Towey, lain Wilson, Martin Dunser, Mike Dobson, Elizabeth Molyneux, Stefan Jochberger, Maria Teresa Leiva, Bruce McCormick and Ulrika Baker for useful comments and additions to the Standards and Data Collection Tool. The study was funded by grants from the Laerdal Foundation, the Association of Anaesthetists of Great Britain and Ireland and the Karolinska Institutet Travel Grant. The funding sources had no role in the design, conduct or reporting of the study.

\section{Author details}

'Department of Physiology and Pharmacology, Section for Anaesthesiology and Intensive Care Medicine, Karolinska Institute, Stockholm, Sweden. ${ }^{2}$ Department of Anaesthesia, Intensive Care and Surgical Services, Karolinska University Hospital, Stockholm 171 76, Sweden. ${ }^{3}$ Department of Anaesthesia and Intensive Care, Muhimbili University of Health and Allied Sciences, Dar es Salaam, Tanzania. ${ }^{4}$ Department of Public Health Sciences, Karolinska Institute, Stockholm, Sweden.

Received: 28 June 2012 Accepted: 21 March 2013

Published: 16 April 2013

\section{References}

1. Razzak JA, Kellermann AL: Emergency medical care in developing countries: is it worthwhile? Bull World Health Organ 2002, 80(11):900-905.

2. Kobusingye OC, Hyder AA, Bishai D, Hicks ER, Mock C, Joshipura M: Emergency medical systems in low- and middle-income countries: recommendations for action. Bull World Health Organ 2005, 83(8):626-631.

3. Dunser MW, Baelani I, Ganbold L: A review and analysis of intensive care medicine in the least developed countries. Crit Care Med 2006, 34(4):1234-1242.

4. Adhikari NK, Rubenfeld GD: Worldwide demand for critical care. Curr Opin Crit Care 2011, 17(6):620-625.

5. Mock C, Kobusingye O, Joshipura M, Nguyen S, Arreola-Risa C: Strengthening trauma and critical care globally. Curr Opin Crit Care 2005 11(6):568-575

6. Cheng AC, West TE, Limmathurotsakul D, Peacock SJ: Strategies to reduce mortality from bacterial sepsis in adults in developing countries. PLoS Med 2008, 5(8):e175.

7. Requejo $\mathrm{JH}$, Merialdi M, Bustreo F: Improving global maternal health: progress, challenges, and promise. Curr Opin Obstet Gynecol 2011, 23(6):465-470

8. Liu L, Johnson HL, Cousens S, Perin J, Scott S, Lawn JE, Rudan I, Campbell H, Cibulskis R, Li M, et al: Global, regional, and national causes of child mortality: an updated systematic analysis for 2010 with time trends since 2000. Lancet 2012, 379(9832):2151-2161.
9. Molyneux E: Paediatric emergency care in developing countries. Lancet 2001, 357(9250):86-87.

10. Amoateng-Adjepong Y: Caring for the critically ill in developing countries-our collective challenge. Crit Care Med 2006, 34(4):1288-1289.

11. English M, Esamai F, Wasunna A, Were F, Ogutu B, Wamae A, Snow RW, Peshu N: Assessment of inpatient paediatric care in first referral level hospitals in 13 districts in Kenya. Lancet 2004, 363(9425):1948-1953.

12. Nolan T, Angos P, Cunha AJ, Muhe L, Qazi S, Simoes EA, Tamburlini G, Weber M, Pierce NF: Quality of hospital care for seriously ill children in less-developed countries. Lancet 2001, 357(9250):106-110.

13. Pearson $L$, Shoo R: Availability and use of emergency obstetric services: Kenya, Rwanda, Southern Sudan, and Uganda. Int J Gynaecol Obstet 2005, 88(2):208-215.

14. Baker T: Critical Care in Low Income Countries. Trop Med Int Health 2009, 14(2):1-9.

15. Human Development Index. http://hdr.undp.org/en/statistics/

16. United Republic of Tanzania, Ministry of Health and Social Welfare: Emergency Obstetric Care Job Aid. Dar es Salaam: United Republic of Tanzania, Ministry of Health and Social Welfare; 2005.

17. United Republic of Tanzania, Ministry of Health and Social Welfare: National Guidelines for Diagnosis and Treatment of Malaria. United Republic of Tanzania, Ministry of Health and Social Welfare. Dar es Salaam: United Republic of Tanzania, Ministry of Health and Social Welfare; 2006.

18. WHO: World Health Statistics. Geneva: World Health Organization; 2012.

19. United Republic of Tanzania, Ministry of Health and Social Welfare: The United Republic of Tanzania: Annual health statistical abstract. Tanzania Mainland. Dar es Salaam: United Republic of Tanzania, Ministry of Health and Social Welfare; 2008.

20. WHO: Guidelines for Essential Trauma Care. Geneva: WHO Press; 2004

21. WHO: Emergency Triage Assessment and Treatment (ETAT). Geneva: WHO Press; 2005.

22. WHO: Pocket Book of Hospital Care for Children. Geneva: WHO; 2005

23. WHO: Surgical care at the district hospital. Geneva: WHO Press; 2003.

24. Global Initiative for Emergency and Essential Surgical Care (GIEESC). http://www.who.int/surgery/globalinitiative/en/.

25. Merry AF, Cooper JB, Soyannwo O, Wilson $\mathrm{IH}$, Eichhorn JH: International Standards for a Safe Practice of Anesthesia 2010. Can J Anaesth 2010, 57(11):1027-1034.

26. Dellinger RP, Levy MM, Carlet JM, Bion J, Parker MM, Jaeschke R, Reinhart K, Angus DC, Brun-Buisson C, Beale R, et al: Surviving Sepsis Campaign: international guidelines for management of severe sepsis and septic shock: 2008. Crit Care Med 2008, 36(1):296-327.

27. Gove S, Tamburlini G, Molyneux E, Whitesell P, Campbell H: Development and technical basis of simplified guidelines for emergency triage assessment and treatment in developing countries. WHO Integrated Management of Childhood Illness (IMCl) Referral Care Project. Arch Dis Child 1999, 81(6):473-477.

28. Tanzania Service Provision Assessment Survey: Tanzania Service Provision Assessment Survey. Dar es Salaam: National Bureau of Statistics, Tanzania; 2006.

29. English M, Esamai F, Wasunna A, Were F, Ogutu B, Wamae A, Snow RW, Peshu N: Delivery of paediatric care at the first-referral level in Kenya. Lancet 2004, 364(9445):1622-1629.

30. Iddriss A, Shivute N, Bickler S, Cole-Ceesay R, Jargo B, Abdullah F, Cherian M: Emergency, anaesthetic and essential surgical capacity in the Gambia. Bull World Health Organ 2011, 89(8):565-572.

31. Jochberger S, Ismailova F, Lederer W, Mayr VD, Luckner G, Wenzel V, Ulmer H, Hasibeder WR, Dunser MW: Anesthesia and its allied disciplines in the developing world: a nationwide survey of the Republic of Zambia. Anesth Analg 2008, 106(3):942-948. table of contents.

32. Bataar O, Lundeg G, Tsenddorj G, Jochberger S, Grander W, Baelani I, Wilson I, Baker T, Dunser MW: Nationwide survey on resource availability for implementing current sepsis guidelines in Mongolia. Bull World Health Organ 2010, 88(11):839-846.

33. Baelani I, Jochberger S, Laimer T, Otieno D, Kabutu J, Wilson I, Baker T, Dunser MW: Availability of critical care resources to treat patients with severe sepsis or septic shock in Africa: a self-reported, continent-wide survey of anaesthesia providers. Crit Care 2011, 15(1):R10.

34. Riviello ED, Letchford S, Achieng L, Newton MW: Critical care in resourcepoor settings: lessons learned and future directions. Crit Care Med 2011, 39(4):860-867. 
35. WHO: Systems thinking for health systems strengthening. Edited by Don de Savigny and Taghreed Adam. Geneva: World Health Organization; 2009

36. WHO: Monitoring emergency obstetric care: a handbook. Geneva: World Health Organization; 2009.

37. Crump JA, Gove S, Parry CM: Management of adolescents and adults with febrile illness in resource limited areas. BMJ 2011, 343:d4847.

38. Abdullah F, Troedsson H, Cherian M: The World Health Organization program for emergency surgical, obstetric, and anesthetic care: from Mongolia to the future. Arch Surg 2011, 146(5):620-623.

39. Konrad D, Jaderling G, Bell M, Granath F, Ekbom A, Martling CR: Reducing in-hospital cardiac arrests and hospital mortality by introducing a medical emergency team. Intensiv Care Med 2010, 36(1):100-106.

40. Chan PS, Jain R, Nallmothu BK, Berg RA, Sasson C: Rapid Response Teams: A Systematic Review and Meta-analysis. Arch Intern Med 2010, 170(1):18-26.

41. Rylance J, Baker T, Mushi E, Mashaga D: Use of an early warning score and ability to walk predicts mortality in medical patients admitted to hospitals in Tanzania. Trans R Soc Trop Med Hyg 2009, 103(8):790-794

42. Molyneux E, Ahmad S, Robertson A: Improved triage and emergency care for children reduces inpatient mortality in a resource-constrained setting. Bull World Health Organ 2006, 84(4):314-319.

43. Watters D, Wilson I, Leaver R, Bagshawe A: Care of the Critically III Patient in the Tropics. Oxford: Macmillan Publishers; 2004

44. Cherian M, Choo S, Wilson I, Noel L, Sheikh M, Dayrit M, Groth S: Building and retaining the neglected anaesthesia health workforce: is it crucial for health systems strengthening through primary health care? Bull World Health Organ 2010, 88(8):637-639.

45. Farmer AP, Legare F, Turcot L, Grimshaw J, Harvey E, McGowan JL, Wolf F: Printed educational materials: effects on professional practice and health care outcomes. Cochrane Database Syst Rev 2008, 3, CD004398.

46. Ayieko P, Ntoburi S, Wagai J, Opondo C, Opiyo N, Migiro S, Wamae A, Mogoa W, Were F, Wasunna A, et al: A multifaceted intervention to implement guidelines and improve admission paediatric care in Kenyan district hospitals: a cluster randomised trial. PLoS Med 2011, 8(4):e1001018.

47. Dunser MW, Festic E, Dondorp A, Kissoon N, Ganbat T, Kwizera A, Haniffa R, Baker T, Schultz MJ: Recommendations for sepsis management in resource-limited settings. Intensiv Care Med 2012, 38(4):557-574.

doi:10.1186/1472-6963-13-140

Cite this article as: Baker et al:: Emergency and critical care services in Tanzania: a survey of ten hospitals. BMC Health Services Research 2013 13:140.

\section{Submit your next manuscript to BioMed Central and take full advantage of:}

- Convenient online submission

- Thorough peer review

- No space constraints or color figure charges

- Immediate publication on acceptance

- Inclusion in PubMed, CAS, Scopus and Google Scholar

- Research which is freely available for redistribution 